\title{
The use of phonemic information to solve anagrams
}

\author{
THOMAS E. FINK and ROBERT W. WEISBERG \\ Temple University, Philadelphia, Pennsylvania 19122
}

\begin{abstract}
Two studies investigated the role of phonemic information in anagram solving. In the first study, subjects were given bigram clues to beginnings of solution words. In addition, some subjects pronounced the letters, either correctly or incorrectly with respect to their pronunciations in the solution words. Correct pronunciations facilitated and incorrect pronunciations inhibited anagram solving. The second study required subjects to repeat the pronunciation of the entire anagram prior to attempting solution. Again, correct pronunciations were solved more quickly than were anagrams containing incorrect phonemic units. Results of the two studies support an analysis of anagram solving in which both orthographic and phonemic information are used to search memory to retrieve possible solution words. The relationship of the present results to recent research concerning reading and other lexical access tasks is discussed.
\end{abstract}

By most accounts, anagram problem solving is considered to be a task involving letter rearrangement and word production (Bourne, Ekstrand, \& Dominowski, 1971). Rearrangement of the letters of an anagram produces implicit letter combinations of varying sizes. One of these new combinations may be "recognized" as a legitimate word of appropriate length and offered as a solution guess (Mayzner, Tresselt, \& Helbock, 1964). Smaller letter groups, on the other hand, are apparently interpreted as potential word parts and are used as probes to search memory and generate word guesses (Dominowski, 1967; Solso, Topper, \& Macey, 1973). In most of these available accounts, there is an implicit assumption that the various letter rearrangements that subjects produce are simply used as clues to what a word or part of a word looks like (i.e., as potential visual or orthographic clues to solution words). However, as Kaplan and Carvellas (1968) have noted, these letter combinations are also usually pronounceable. There is thus the additional possibility that letter combinations could function as phonemic clues to solution wordsclues to how a word or part of a word may sound and/ or be articulated.

To date, no research attention has been given to the facilitative use of phonemic information to solve anagrams. Rather, research results suggest that, whenever phonemic encoding occurs in anagram solving, solution is inhibited. Studies have demonstrated relatively slow solution times for anagrams that are rated as easy to

The authors wish to thank Lynn Hasher, Roger Dominowski, and an anonymous reviewer for their criticisms and suggestions concerning an earlier draft of the paper. Requests for reprints should be sent to Robert Weisberg, Department of Psychology, Weiss Hall, 6th Floor, Temple University, Philadelphia, Pennsylvania 19122. pronounce (Hebert \& Rogers, 1966) and for anagrams pronounced by subjects before the attempt at solution (Dominowski, 1969). These negative results produced by anagram pronunciation have been taken as support for the Gestalt view that pronunciation produces an organization of the anagram, and this organization interferes with the reorganization necessary to solve the anagram (Bourne et al., 1971, pp. 86-87). From this viewpoint, phonemic encoding simply inhibits the usual solution processes, which involve letter rearrangement.

However, there are reasons to believe that the phonemic encoding of anagrams may be an important positive factor in anagram solution. This hypothesis is indirectly supported by data and theory in a number of areas not directly concerned with anagrams. Research concerned with visual search, word recognition, and reading processes suggests that letters and letter units, including nonword combinations, are given phonemic codes (e.g., Conrad, 1964; Krueger, 1970; Rubenstein, Lewis, \& Rubenstein, 1971) and that this process of phonemic encoding can play an important role aiding lexical access (cf. Levy, 1977; Meyer, Schvaneveldt, \& Ruddy, 1974). At one point, it was claimed that phonemic encoding is an automatic component of lexical access (e.g., Rubenstein et al., 1971). More recently, however, it has been argued that lexical access can occur through either visual or phonological codes (e.g., Coltheart, Davelaar, Jonasson, \& Besner, 1977).

Although it is speculative at this point, one could apply this viewpoint to anagrams. ${ }^{1}$ Rather than analyzing anagrams as problems involving the rearrangement of letters until a word is produced, one could conceptualize an anagram as a lexical access task. The anagram, as presented, is a cue for word retrieval, and the first step involves encoding the anagram, visually (ortho- 
graphically), phonologically, or in both ways. Therefore, if a letter combination is actually contained in a solution word, and if the phonemic encoding given the letter combination is correct with respect to its pronunciation in the solution word, solution should be facilitated.

A number of observations from research conducted in our laboratory also support the notion that phonemic encoding plays an important role in anagram solving, related to the retrieval of potential solution words. First, many subjects produce several different pronunciations of the same letter rearrangements during solution attempts. Also, some pronunciations of nonsolution letter rearrangments appear to be the basis for solution word guesses. For example, one subject working on the anagram ARFUD (fraud) produced the phonemic unit "far-ud." He then quickly offered the similarly sounding word "forehead" as a solution guess. Finally, evidence for the general importance of phonemic encoding in anagram solving has also been provided in situations in which subjects have failed to solve problems apparently because they incorrectly pronounced otherwise correct letter rearrangements. This occurred in our work for the anagram EVPOR (prove), when subjects correctly rearranged the letters to spell p-r-o-vee, but pronounced them to rhyme with "stove." Solution was never obtained in several of these cases.

The possibility that subjects attempt to use phonemic encodings to solve anagrams provides an interesting interpretation for why easy-to-pronounce anagrams, including word anagrams (Beilin \& Horn, 1962; Devnich, 1937; Ekstrand \& Dominowski, 1965), anagrams rated easy to pronounce (Herbert \& Rogers, 1966), and anagrams pronounced prior to solution (Dominowski, 1969), are relatively difficult to solve. These situations all provide subjects with salient phonemic encodings of particular anagram letter sequences. Subjects may initially attempt to use both the intact letter combinations (Fink \& Dominowski, 1974) and their phonemic encodings to aid word production. If subjects do this, they will probably be misled, since it is unlikely that either intact letter combinations from the anagram, or their phonemic encodings, are contained in anagram solution words. Gestalt notions, which suggest that word anagrams or other easily pronounced anagrams are well organized structures that actively resist being broken apart (e.g., Beilin \& Horn, 1962; Bourne et al., 1971, pp. 86-87; Devnich, 1937), are therefore somewhat misleading. Easily pronounced anagrams initially may remain unchanged and unsolved simply because the form in which they are originally presented provides subjects with the information they need in order to start lexical access operations. Only after failing in these attempts to retrieve the solution word will subjects begin to rearrange an anagram's letters.

The following two studies were designed to provide explicit demonstrations of the role of phonemic encoding in anagram solving. In addition to the applicability of such research, this demonstration relates aspects of anagram solving to other cognitive processes, as mentioned above. This relationship is a potentially important one that, to date, has not been adequately explored. The first study presented here investigated the influence of explicit phonemic clues to portions of anagram solution words, and the second examined the influence of phonemic encodings of entire anagrams.

\section{EXPERIMENT 1}

The possible use of phonemic encodings in anagram solving was first investigated using a variation of a clueing procedure developed by Dominowski (1968). Subjects were presented letter combinations and position clues to solution words at the same time that they heard the letter combinations pronounced. For example, given the anagram BLAOR (labor), some subjects were shown the clue LA___ and heard it pronounced "lay."

Three groups were tested, all of which received the same anagrams. A visual information group saw simply the first two letters of the solution word prior to each anagram presentation. A correct phonemic group saw the two clue letters, heard them pronounced approximately as they would be pronounced in the solution word, and then pronounced the letters themselves. For example, prior to the presentation of an anagram such as BLAOR, these subjects heard and pronounced the clue LA as "lay." An incorrect phonemic group also saw the two letters but heard and pronounced them incorrectly with respect to how they would be pronounced in the solution word. For an anagram such as BLAOR, these subjects heard and pronounced the clue LA as "lah." The subjects in the correct phonemic group were told that in every case the pronunciation they heard was correct and, if used, would help them solve the anagrams. The subjects in the incorrect phonemic group were told that the pronunciation they heard was incorrect in every case. A group that heard an incorrect pronunciation of the clue, but was led to believe it was useful, was not included in the present study, because it would have been difficult to maintain the effect of this manipulation. After a few problems, these subjects would know the pronunciation was incorrect, and it would then be impossible to know what these subjects did with the pronunciation clue on subsequent problems.

The correct phonemic group was expected to solve the anagrams faster than either the incorrect phonemic or the visual information groups, since the former had an additional clue about the solution word. Although it was possible that subjects in the visual information group would independently produce a correct phonemic encoding of the letter clues at the time the letters were presented, the letter clues were sufficiently ambiguous that no consistently correct phonemic encoding was expected to occur for all visual information subjects. The incorrect pronunciation group was included to test 
an interpretation of an acoustic perseverance hypothesis, originally suggested by Beilin and Horn (1962) to explain why word anagrams might be more difficult to solve than nonsense anagrams. According to this hypothesis, a subject will perseverate on the sound of a letter sequence and discontinue or restrict the activity of normal anagram solving. This idea has also been suggested to account for the greater difficulty subjects experience working on easy-to-pronounce anagrams (Herbert \& Rogers, 1966) and anagrams pronounced prior to testing (Dominowski, 1969). The acoustic perseverance hypothesis is of interest because, in a radical form, it implies that both the correct and incorrect phonemic groups should perform worse than the visual information group.

\section{Method}

Materials. Anagrams were formed from 30 five-letter English nouns and adjectives. All words began with initial consonantvowel bigrams, contained two or three syllables, and had no repeated letters. Thorndike-Lorge (1944) frequency ratings for these words varied from 1 to AA. Anagrams had either single solutions (Olson \& Schwartz, 1967) or very low-frequency alternative solutions. The letter orders for the anagrams were determined by using Tresselt and Mayzner's (1966) ranking of possible letter orders for five-letter words. The letter order most different from that of the solution word was assigned to the highest Thorndike-Lorge frequency word. The second most different letter order was assigned to the second most frequent word, and so on. All anagrams were typed in capital letters on plain index cards. Two cards were used for each anagram problem. The first contained the initial bigram clue; the second contained the anagram as well as the clue, with the clue placed directly beneath the anagram. The anagrams are presented in Appendix A.

The anagrams were presented in a different order to each subject, with the constraints that each anagram order be presented to one subject in each of the three groups and that each anagram appear equally often in the first and second halves of the lists.
Procedure. For each problem, an initial bigram clue card was presented for $2 \mathrm{sec}$, followed by the anagram card. For the correct phonemic and incorrect phonemic groups, the initial bigram clue was pronounced by the experimenter at the same time the clue card was presented. During the 2-sec exposure period, these subjects were instructed to repeat the pronunciation of the clue once, exactly as they heard it. The correct phonemic group was told that both the letters and the pronunciation they heard were clues to the beginning of the solution word and that this pronunciation would help them to solve the anagram. The incorrect phonemic group was told that the two letters they saw were initial bigram clues but that the pronunciation they heard and repeated was incorrect. The visual information group was told that the two letters they would see were the first two letters of the solution word, and these subjects were instructed only to look at the clue for the $2-\mathrm{sec}$ exposure period.

After instructions, subjects were given four practice anagram problems. During actual testing, subjects were given $18 \mathrm{sec}$ to solve each anagram. Pilot work revealed that $18 \mathrm{sec}$ were sufficient for the majority of subjects to solve each anagram. All subjects were individually tested, and solution times were obtained from a hand-held stopwatch and rounded off to the nearest $1 \mathrm{sec}$. If an anagram was not solved during the 18 -sec period, the subject was told the solution and given the next anagram.

Subjects. Sixty-six male and female volunteer subjects were obtained from a pool of Temple University students enrolled in introductory psychology. The subjects received course credit for their participation. None of the subjects had previously taken part in anagram research, and all spoke English as their native language.

\section{Results and Discussion}

Data analyses were performed in two ways: on scores collapsed across subjects, so that the anagram was the replicate (Fink \& Dominowski, 1974), and on scores collapsed across anagrams, so that the subject was the replicate. These data are presented in Tables 1 and 2 , respectively. Median and mean solution times were computed for the entire series of anagrams within each

Table 1

Anagram Solution Times (in Seconds) for Experiment 1, Analyzed Across Subjects

\begin{tabular}{|c|c|c|c|c|c|c|c|c|c|c|}
\hline \multirow[b]{2}{*}{ Group } & \multicolumn{3}{|c|}{$\begin{array}{c}\text { First Half of } \\
\text { Anagram Series }\end{array}$} & \multicolumn{3}{|c|}{$\begin{array}{l}\text { Second Half of } \\
\text { Anagram Series }\end{array}$} & \multicolumn{4}{|c|}{ Total } \\
\hline & Median & Mean & SD & Median & Mean & $\mathrm{SD}$ & Median & Range & Mean & SD \\
\hline Correct Phonemic & 3.0 & 4.0 & 1.9 & 2.5 & 3.9 & 3.7 & 2.5 & $1.3-11.2$ & 3.5 & 2.2 \\
\hline Visual Information & 3.5 & 4.8 & 3.7 & 4.0 & 4.3 & 2.7 & 3.4 & $1.5-17.5$ & 4.5 & 3.4 \\
\hline Incorrect Phonemic & 4.0 & 5.5 & 3.9 & 3.0 & 4.4 & 3.2 & 4.0 & $2.0-17.6$ & 4.9 & 3.3 \\
\hline
\end{tabular}

Note-Both medians and means were computed from a distribution of median scores for each anagram, collapsed across subjects.

Table 2

Anagram Solution Times (in Seconds) for Experiment 1, Analyzed Across Anagrams

\begin{tabular}{|c|c|c|c|c|c|c|c|c|c|c|}
\hline \multirow[b]{2}{*}{ Group } & \multicolumn{3}{|c|}{$\begin{array}{c}\text { First Half of } \\
\text { Anagram Series }\end{array}$} & \multicolumn{3}{|c|}{$\begin{array}{l}\text { Second Half of } \\
\text { Anagram Series }\end{array}$} & \multicolumn{4}{|c|}{ Total } \\
\hline & Median & Mean & SD & Median & Mean & SD & Median & Range & Mean & SD \\
\hline Correct Phonemic & 3.2 & 3.5 & 2.0 & 2.5 & 3.0 & 1.4 & 2.8 & $1.3-8.5$ & 3.3 & 1.6 \\
\hline Visual Information & 3.5 & 4.2 & 2.1 & 3.4 & 4.1 & 2.3 & 3.4 & $1.4-10.5$ & 4.2 & 2.0 \\
\hline Incorrect Phonemic & 3.7 & 4.7 & 3.0 & 3.2 & 3.8 & 1.9 & 3.3 & $2.1-10.5$ & 4.1 & 2.0 \\
\hline
\end{tabular}

Note-Both medians and means were computed from a distribution of median scores for each anagram, collapsed across subjects. 
condition, as well as for the first and second halves of the series. Appendix A may be consulted for descriptive statistics for each of the 30 anagrams. Differences among groups were evaluated with nonparametric statistics, because the distributions of median scores were all highly skewed. Concerning the data in Table 1 , the Friedman test was first used to evaluate differences among the three conditions. Significant differences were found for the overall medians $\left[\chi^{2}(2)=19.40, p<.001\right\rceil$. for the first-half scores $\left[\chi^{2}(2)=17.72, p<.001\right]$ and for the second-half scores $\left[\chi^{2}(2)=7.65, p<.025\right]$. Sign tests were used to assess differences between pairs of groups for the overall, first-half, and second-half scores. These tests were conducted by determining how frequently the median scores for each of the 30 pairs of anagrams differed in the direction predicted. For the overall comparisons, the correct phonemic group performed better than both the incorrect phonemic group $(\mathrm{z}=3.06, \mathrm{p}<.002$, one-tailed test $)$ and the visual information group $(z=3.16, p<.001$, one-tailed test $)$. The difference between the visual information and incorrect phonemic groups was not significant. For the first-half session scores, all three differences were significant: The correct phonemic group performed better than both the incorrect phonemic group $(z=2.95$, $\mathrm{p}<.002$, one-tailed test) and the visual information group $(\mathrm{z}=1.83, \mathrm{p}<.05$, one-tailed test $)$, and the visual information group performed better than the incorrect phonemic group $(\mathrm{z}=2.34, \mathrm{p}<.02$, two-tailed test $)$. For the second-half scores, the difference between the correct phonemic and incorrect phonemic groups was significant $(z=2.08, p<.02$, one-tailed test $)$, and the difference between the correct phonemic and visual groups was significant $(\mathrm{z}=2.01, \mathrm{p}<.025$, one-tailed test).

Comparable results were obtained when the data in Table 2, collapsed across anagrams, were analyzed. Overall median differences among the three conditions were again significant $\left[\chi^{2}(2)=7.93, p<.025\right]$. Sign tests were used to evaluate the number of matched pairs of median scores that differed in the direction predicted. For this comparison, the difference between the correct phonemic and visual groups was significant $(\mathrm{z}=2.34, \mathrm{p}<.01$, one-tailed test $)$, and the difference between the correct phonemic and incorrect phonemic groups approached significance $(z=1.49, p<.07$, one-tailed test). Changes in performance from the first half to the second half of the test session were also evaluated within each condition by comparing each subject's median first-half score with his or her own median second-half score. Sign tests were used to compare the number of subjects within each group whose median score decreased from the first to the second half with the number of subjects whose median score increased from the first half to the second half. The only change in performance that was significant was the decrease in solution times from the first half to the second half for the incorrect phonemic group $(z=2.08$, $\mathrm{p}<.05$, two-tailed test).

The hypothesis that subjects can use phonemic information to help solve anagrams was therefore supported by these data analyses. The notion that subjects will perseverate on a phonemic encoding known to be incorrect was partially supported, since the overall and second-half differences between the visual information and incorrect phonemic groups were not significant. However, this difference was significant for the first-half scores, which indicates that, initially, the "incorrect" phonemic encodings for the bigram clues were detrimental. The failure to find this difference for the second half of the session and the finding that the incorrect phonemic group significantly improved in performance from the first to the second half of the test session indicate that, if the first-half detrimental effect was due to acoustic perseveration, subjects can learn to either ignore or eliminate this effect.

These results thus demonstrate that the occurrence of phonemic encodings of anagram letter combinations does not necessarily interfere with anagram solving. The critical variable in this regard appears to be the relationship between the pronunciation of the letter combination in the anagram and in the solution word. If a letter combination in the anagram is pronounced similarly to the way it is pronounced in the solution word, anagram solving is facilitated.

\section{EXPERIMENT 2}

Experiment 2 was designed to investigate the influence of phonemic information supplied as part of the pronunciations of entire anagrams. We have suggested that when anagram solvers are given pronounceable anagrams to solve, they are provided with both orthographic and phonemic information, which initially may be used to search memory and produce words. However, the use of this information is likely to be misleading if the letters in the anagram are in an order greatly different from their order in the solution word. On the other hand, if an anagram contains a letter combination that is intact in the solution word and if this combination is pronounced "correctly," solution may be facilitated. This notion was tested by systematically controlling the pronunciation of pronounceable anagrams, at the time the anagrams were presented. For example, the anagram LATVI (vital) could be presented as "lat-vie" or "lat-vee." In the first pronunciation, the letters VI are pronounced similarly to their pronunciation in the solution word. If phonemic encodings are used in the way suggested, subjects receiving anagrams that contained "correct" phonemic encodings of letter combinations from the solution word would be expected to solve the problems faster than would subjects who received "incorrect" phonemic encodings of these same letter combinations. 


\section{Method}

Materials. Eighteen anagrams were formed from five-letter English words. The solution words varied from 1 to $\mathrm{AA}$ in Thorndike-Lorge (1944) frequency. Solution words were chosen with two additional constraints: The words all began with a consonant-vowel letter combination that could be pronounced in at least two different ways, and the letters of the words could be rearranged to form either the solution word alone (Olson \& Schwartz, 1967) or the solution word plus a very low-frequency alternative. The anagrams are presented in Appendix B.

The anagrams were formed so that the first two or three letters of the solution words were intact in some position in the anagram. In addition, the entire anagram had to be capable of being pronounced two different ways, one of which would contain a pronunciation of the intact letter combination that was approximately the same as the combination's pronunciation in the solution word. As a further example, the anagram GLOCI (logic) provided two possibilities: "glah-see" and "glow-see." In the "glah-see" pronunciation, the letter unit LO is pronounced similarly to the way it is pronounced in the solution word. Anagram pronunciations of this type were used for the correct pronunciation group. In the "glow-see" pronunciation, the letter unit LO is pronounced differently from the way it is pronounced in the solution word. Pronunciations of this type were used for the incorrect pronunciation group. The correct and incorrect pronunciations were also controlled for any major difference in ease of pronounceability that appeared obvious to the experimenter.

Thirteen presentation orders were obtained for the set of problems. These orders were then inverted so that a different presentation order was obtained for each of 26 pairs of subjects. All subjects received the same anagrams.

All anagrams were typed in capital letters on plain index cards, with a space between each letter.

Procedure. Subjects were individually tested by the same experimenter. After the subject had received and understood the instructions and testing procedures, the experimenter pronounced the first anagram. At a signal (a click), the subject was instructed to repeat the anagram twice, the same way it was pronounced by the experimenter. At a second signal, $3 \mathrm{sec}$ after the first, the subject was shown the anagram and instructed to pronounce it one more time the same way the experimenter did. At a third signal (a click and a light), 3 sec after the second signal, the subject was instructed to begin to try to solve the anagram. Subjects were given $25 \mathrm{sec}$ to work on each anagram. Pilot work revealed this amount of time was sufficient for a majority of subjects to solve the anagrams. If solution did not occur within this time, the subject was told the solution word, and the next anagram was presented in the same manner.
Solution times were recorded with a hand-operated Automated Data Systems 1248B timer/counter. This apparatus also controlled the occurrence of signals in the experiment. Solution times were rounded off to the nearest $.01 \mathrm{sec}$ and recorded by the experimenter.

Subjects were given four practice anagrams prior to the start of the experiment.

Subjects. Fifty-two male and female volunteers were recruited from Temple University students enrolled in an introductory psychology course. The subjects received course credit for participating. None had previously taken part in anagram research, and all spoke English as their native language.

\section{Results and Discussion}

Median and mean solution times were computed for distributions of median solution times obtained with both anagrams and subjects as replicate. Mean proportions of anagrams solved for each condition were also computed. Overall, first-half, and second-half scores for these variables are reported in Tables 3 and 4. Descriptive statistics for each of the 18 anagrams are presented in Appendix B.

Differences between conditions were evaluated first by comparing the number of problems solved for each group, collapsed across subjects and across anagrams. In the anagram-as-replicate analysis, the overall difference was significant $[t(17)=3.03, p<.005$, one-tailed test] and the first-half difference was significant $[\mathrm{t}(17)=2.93$, $\mathrm{p}<.005$, one-tailed test]. In the subject-as-replicate analysis, only the first-half difference was significant $[\mathrm{t}(50)=2.05, \mathrm{p}<.025$, one-tailed test $]$.

The data in Table 3, collapsed across anagrams, were analyzed using median tests, with a transformation of $\mathrm{z}=\sqrt{\mathrm{x}^{2}}$ in order to make possible tests of directional predictions (Hayes, 1963, p. 585). For the overall score, the difference between groups was significant $(\mathrm{z}=1.66, \mathrm{p}<.05)$. No other differences between the correct and incorrect pronunciation groups was significant.

The data in Table 4, collapsed across subjects, were analyzed using Wilcoxon tests. For the overall scores, the difference between groups was significant $(Z=2.05$,

Table 3

Anagram Solution Times (in Seconds) and Proportions of Problems for Experiment 2, Analyzed Across Subjects

\begin{tabular}{|c|c|c|c|c|c|c|}
\hline \multirow[b]{2}{*}{ Group } & \multicolumn{4}{|c|}{ Solution Time } & \multicolumn{2}{|c|}{ Proportion Solved } \\
\hline & Median & Range & Mean & SD & Mean & SD \\
\hline & \multicolumn{6}{|c|}{ First Half of Anagram Series } \\
\hline \multirow[t]{2}{*}{ Incorrect Phonemic } & $\begin{array}{l}21.33 \\
25.00\end{array}$ & $\begin{array}{l}1.79-25.00 \\
3.03-25.00\end{array}$ & $\begin{array}{l}15.55 \\
18.07\end{array}$ & $\begin{array}{r}10.04 \\
8.92\end{array}$ & $\begin{array}{l}.62 \\
.51\end{array}$ & $\begin{array}{l}.24 \\
.27\end{array}$ \\
\hline & \multicolumn{6}{|c|}{ Second Half of Anagram Series } \\
\hline \multirow[t]{2}{*}{ Incorrect Phonemic } & $\begin{array}{l}15.20 \\
16.92\end{array}$ & $\begin{array}{l}1.20-25.00 \\
2.24-25.00\end{array}$ & $\begin{array}{l}14.38 \\
16.18\end{array}$ & $\begin{array}{l}9.14 \\
9.07\end{array}$ & $\begin{array}{l}.58 \\
.58\end{array}$ & $\begin{array}{l}.26 \\
.25\end{array}$ \\
\hline & \multicolumn{6}{|c|}{ Total } \\
\hline $\begin{array}{l}\text { Correct Phonemic } \\
\text { Incorrect Phonemic }\end{array}$ & $\begin{array}{l}19.96 \\
24.59\end{array}$ & $\begin{array}{l}1.76-25.00 \\
2.56-25.00\end{array}$ & $\begin{array}{l}15.64 \\
17.95\end{array}$ & $\begin{array}{l}9.82 \\
9.27\end{array}$ & $\begin{array}{l}.60 \\
.55\end{array}$ & $\begin{array}{l}.23 \\
.25\end{array}$ \\
\hline
\end{tabular}

Note-Solution times were computed from a distribution of median scores for each anagram, collapsed across subjects. Proportions were also calculated for an anagram-as-replicate analysis. 
Table 4

Anagram Solution Times (in Seconds) and Proportions of Problems Solved for Experiment 2, Analyzed Across Anagrams

\begin{tabular}{|c|c|c|c|c|c|c|}
\hline \multirow[b]{2}{*}{ Group } & \multicolumn{4}{|c|}{ Solution Time } & \multicolumn{2}{|c|}{ Proportion Solved } \\
\hline & Median & Range & Mean & SD & Mean & SD \\
\hline & \multicolumn{6}{|c|}{ First Half of Anagram Series } \\
\hline \multirow[t]{2}{*}{ Incorrect Phonemic } & $\begin{array}{l}12.34 \\
17.77\end{array}$ & $\begin{array}{l}2.05-25.00 \\
1.91-25.00\end{array}$ & $\begin{array}{l}14.33 \\
17.21\end{array}$ & $\begin{array}{l}8.41 \\
7.91\end{array}$ & $\begin{array}{l}.61 \\
.52\end{array}$ & $\begin{array}{l}.20 \\
.14\end{array}$ \\
\hline & \multicolumn{6}{|c|}{ Second Half of Anagram Series } \\
\hline \multirow[t]{2}{*}{ Incorrect Phonemic } & $\begin{array}{l}14.51 \\
15.46\end{array}$ & $\begin{array}{l}1.38-25.00 \\
1.40-25.00\end{array}$ & $\begin{array}{l}15.26 \\
15.24\end{array}$ & $\begin{array}{l}7.82 \\
9.12\end{array}$ & $\begin{array}{l}.59 \\
.58\end{array}$ & $\begin{array}{l}.17 \\
.24\end{array}$ \\
\hline & \multicolumn{6}{|c|}{ Total } \\
\hline $\begin{array}{l}\text { Correct Phonemic } \\
\text { Incorrect Phonemic }\end{array}$ & $\begin{array}{l}13.94 \\
21.55\end{array}$ & $\begin{array}{l}3.68-25.00 \\
3.59-25.00\end{array}$ & $\begin{array}{l}14.75 \\
17.21\end{array}$ & $\begin{array}{l}7.65 \\
8.57\end{array}$ & $\begin{array}{l}.60 \\
.55\end{array}$ & $\begin{array}{l}.14 \\
.14\end{array}$ \\
\hline
\end{tabular}

Note-Solution times were computed from a distribution of median scores for each subject, collapsed across anagrams. Proportions were also calculated from this subject-as-replicate analysis.

$p<.025$, one-tailed test). The groups were also significantly different for the first half scores $(Z=2.24$, $\mathrm{p}<.025$, one-tailed test).

These results thus support the idea that experimentersupplied pronunciations of anagrams will be used by subjects to aid in the production of potential solution words. Anagrams containing letter units that are pronounced similarly to their pronunciations in their respective solution words are solved faster than are anagrams in which these letter units are pronounced differently from their pronunciations in solution words. In this situation, anagram pronunciations appear to supply phonemic information that functions as clues to potential solution words.

As in Experiment 1, the present results indicated that subjects can learn to overcome negative effects due to incorrect phonemic information. Not only was the difference between the correct phonemic and incorrect phonemic groups not significant for the second half of the list of anagrams, but also an anagramas-replicate analysis of the first-vs. second-half increase in rate of solution for the incorrect phonemic groups revealed a significant difference $[\mathrm{t}(17)=1.76, \mathrm{p}<.05$, one-tailed test]. Subjects consistently exposed to misleading phonemic encodings of anagram letter sequences apparently learn either to ignore these pronunciations or, perhaps, to use the incorrect pronunciations to produce alternative pronunciations, which are more likely to be correct and helpful. These subjects were able to learn this without being told by the experimenter that the pronunciations would be misleading. Little support is thus provided for the acoustic perseveration hypothesis.

Finally, these results also support the proposed description of what may occur when subjects are given word anagrams and other easily pronounced anagrams to solve and why such anagrams are relatively difficult to solve. The phonemic encodings of these anagrams are apparently used to aid the search for and production of potential solution words. The effect of anagram pronounceability thus may be understood as the result of its negative impact on both the letter rearrangement and word production processes in anagram solving. Not only are easy-to-pronounce anagrams more likely than hard-to-pronounce anagrams to be maintained for a longer period of time in an incorrect letter order (Fink \& Dominowski, 1974), but these anagrams also appear to initiate memory search and word production based on what are usually incorrect orthographic and phonemic clues.

\section{GENERAL DISCUSSION}

\section{Solving Anagrams}

In general, the results of both studies indicate that phonemic information can be used to help solve anagrams. A facilitative role was found when phonemic information was given as explicit clues to the initial portions of solution words, as well as when subjects were asked simply to pronounce entire anagrams. Subjects were also able to learn to overcome negative effects caused by misleading phonemic encodings of solution word letter parts. The word production process in anagram solving may thus be the result of the same sort of memory search and retrieval operations that function during other word recognition and recall tasks. Phonemic information is helpful to the production of anagram solution words because it is one of a number of attributes in the long-term memory representations of words that may contribute to word recognition and recall (cf. Brown \& McNeill, 1966; Kintsch, 1970; Underwood, 1969).

The present account of the use of phonemic information in anagram solving is useful in explaining why easy-to-pronounce anagrams, including word anagrams, are relatively difficult to solve. Rather than inhibiting letter rearrangement because of acoustic perseveration, pronounceable anagrams simply appear to provide subjects readily available memory search probes that are unlikely to be accurate clues to actual solution 
words. This understanding of the role of phonemic information in anagram solving also provides a possible explanation for why anagram solvers who appear to construct solution words properly sometimes fail to recognize them as words (e.g., Beilin \& Horn, 1962). For example, Schwartz (1968) has reported that subjects in his study had unusual and surprising difficulty solving anagrams constructed from the word "sea." He noted that many of these subjects tried the SEA letter combination but failed to recognize it as a word. Perhaps this occurred because the correct letter combination was given an incorrect phonemic encoding. For example, the EA combination in SEA may have been pronounced as "see-a," which might interfere with lexical access.

\section{Anagrams as Lexical Access Tasks}

The present results may open the way for a broadening of our conceptualization of how anagrams are solved. As mentioned earlier, the traditional view of anagram solving holds that high-frequency letters and/or letter combinations are extracted from the anagram by the subject, and these combinations serve as the basis for word-construction attempts (e.g., Bourne et al., 1971, pp. 82-88; Kaplan \& Carvellas, 1968). The present findings raise the possibility that phonemic encoding might occur independently of actual letter rearrangement, and this phonemic encoding can then serve as the basis for lexical access and solution word retrieval. An example of the importance of phonemic encoding was given in the introduction, in which the performance of a subject solving the anagram ARFUD (fraud) was discussed. This subject produced the phonemic encoding "far-ud," and followed it with "forehead" as an incorrect solution guess. The interesting question at this point concerns the basis for the "far-ud" encoding, since "far" is not an intact unit in the anagram. There are at least three possibilities: It might be due to a visual rearrangement of the letters (an imaginary rearrangement); it might be due to an initial phonemic encoding (e.g., "arf" cues "far"); or it might be due to parallel visual processing of the letters in the anagram, which then are encoded phonemically (e.g., a-r-f is encoded in parallel and cues the phonemic encoding "far"). At present, no data are available to enable us to differentiate among these speculations, but the important point is that those speculations might not have been formulated, based on the traditional view of anagrams as letter-rearrangement problems.

At this point, it would be of value to consider the relationship between anagrams and other lexical access tasks in more detail, because it will point out some interesting implications of the present view. Much present-day interest in lexical access tasks stems from the recent upsurge of work in reading. In reading aloud, the reader is presented a visual string, and he or she must produce a phonemic encoding for the string (i.e., the reader must "say the words aloud"). As mentioned earlier, one specific question of some interest to theorists in this area concerns the role of phonemic encoding in providing access to the lexical unit that represents the word in memory. A related question concerns the basis for a reader's ability to phonemically encode novel strings of letters (i.e., to read pseudowords aloud). Consider a pseudoword such as "hean." Mature readers of English have no trouble reading this string, although they have never seen it before. Glushko (1979) has recently argued that the ability to read aloud depends on a process in which the letter string is matched with other strings in memory. If the string completely matches a string in memory, then the string is a familiar word, and the pronunciation can simply be recalled. In the case of a pseudoword, however, there is no complete match, so the capacity to read the word depends upon a partial match between letter strings in the pseudoword and corresponding strings in words. So, for example, the pseudoword "hean" would be pronounced based on the partial correspondences between it and such words as "heat," "hear," and "bean." There is experimental evidence available to support this view (Bauer \& Stanovich, 1980; Glushko, 1979).

Let us now consider the processes that might be involved in solving a visually presented anagram. First, the visual stimulus is not familiar, so the initial situation corresponds to presentation of a pseudoword in a reading task. Production of a phonemic encoding would therefore depend upon partial matches between the anagram string and familiar words. Therefore, Glushko's (1979) reading model might be helpful in explaining the particular phonemic encodings that subjects give to particular anagrams.

Once the subject has produced a phonemic encoding for the anagram the task becomes more like listening to dictation than like reading. That is, the person is now trying to determine if an auditory string is a word, perhaps in conjunction with a visual string, perhaps independently. Thus, solving anagrams may be more complicated than reading.

One final point concerns the relationship between phonemic encoding and lexical access, in reading and in solving anagrams. As mentioned earlier, there is evidence that phonemic encoding during reading occurs after lexical access (Bauer \& Stanovich, 1980; Glushko, 1979). That is, phonemic encoding occurs after the visual string is matched with other letter strings in memory. Although Glushko's model is not directly concerned with it, consider the situation in which a person is given an auditory string of letters and is asked if the letters spell a word. Based on an analogy to Glushko's analysis of the visual case, one might expect that the string of auditory letters (say, "p-r-o-ve") would be matched with sequences in memory. If a complete match is made, then the person recognizes the string and pronounces it correctly. However, one problem with this view is that it cannot explain the fact 
that several of our subjects produced the letter string $\mathrm{p}-\mathrm{r}-\mathrm{O}-\mathrm{v}-\mathrm{e}$ in attempting to solve an anagram but pronounced it to thyme with "stove" and did not recognize it as a word. This result would seem to require that pronunciation occur before lexical access, which may contradict Glushko's (1979) model. An identical result can be seen in the well-known party game in which a person is asked to give the only four-letter English word ending in e-n-y. The person dutifully goes through the alphabet and invariably pronounces d-e-n-y as "denny" and does not solve the problem.

Although the results just discussed involve phonemic encoding for auditory strings of letters, it would seem at first glance that models of reading, as specific cases of models of lexical access, should be able to deal with them. Therefore, for our purposes, the important point is that data from anagram research may be relevant to theory in other areas.

As a final point, it should be noted that theory and research concerning anagrams has become scarce in recent years. As an example of this lack of interest, an examination of several recent texts concerning cognitive processes shows no reference to anagrams in the indexes of these books (e.g., Bourne, Dominowski, \& Loftus, 1979; Glass, Holyoak, \& Santa, 1979; Solso, 1979). The present viewpoint might help to stimulate a revival of interest in anagrams, because it may be more fruitful to conceive of them as tasks involving lexical access, rather than solely as problem solving tasks, involving a search through combinations of letters.

\section{REFERENCES}

Bauer, D. W., \& Stanovich, K. E. Lexical access and the spelling-to-sound regularity effect. Memory \& Cognition, 1980, $8,424-432$.

BeILIN, J., \& HoRn, R. Transition probability effects in anagram problem solving. Journal of Experimental Psychology, 1962, 63, 514-518.

Bourne, L. E., JR., Dominowski, R. L., \& Loftus, E. F. Cognitive process. Englewood Cliffs, N.J: Prentice-Hall, 1979.

Bourne, L. E., Jr., Erstrand, B. R., \& Dominowski, R. L. The psychology of thinking. Englewood Cliffs, N.J: PrenticeHall, 1971.

Brown, R., \& McNeILl, D. The "tip of the tongue" phenomenon. Journal of Verbal Learning and Verbal Behavior, 1966, 5, 325-337.

Coltheart, M., Davelaar, E., Jonagson, J. T., \& Besner, D. Access to the internal lexicon. In S. Dornic (Ed.), Attention and performance VI. Hillsdale, N.J: Erlbaum, 1977.

Conrad, R. Acoustic confusions in immediate memory. British Journal of Psychology, 1964, 55, 75-84.

Devnich, G. E. Words as "Gestalten." Journal of Experimental Psychology, 1937, 20, 297-300.

Dominowski, R. L. Anagram solving as a function of bigram rank and word frequency. Journal of Experimental Psychology, $1967,75,299-306$.

DominowsKi, R. L. Anagram solving as a function of letter sequence information. Journal of Experimental Psychology, $1968,76,78-83$.

Dominowsxi, R. L. The effect of pronunciation practice on anagram difficulty. Psychonomic Science, 1969, 16, 99-100.

Ekstrand, B. R., \& Dominowski, R. L. Solving words as anagrams. Psychonomic Science, 1965, 2, 239-240.

Fink, R. S., \& Dominowski, R. L. Pronounceability as an explanation of the difference between word and nonsense anagrams. Journal of Experimental Psychology, 1974, 102, 239-240.

Glass, A. L., Holyonk, K. J., \& Santa, J. L. Cognition. Reading, Mass: Addison-Wesley, 1979.

GLUShKo, R. The organization and activation of orthographic knowledge in reading aloud. Joumal of Experimental Pyychology: Human Perception and Performance, 1979, 5, 674-691.

Hayes, W. L. Statistics for psychologists. New York: Holt, Rinehart, \& Winston, 1963.

Hebert, J. A., \& Rogers, C. A., Jr. Anagram solution as a function of pronounceability and difficulty. Psychonomic Science, 1966, 4, 359-360.

KAPLAN, I. T., \& CARVELlas, T. Effect of word length on anagram solution time. Journal of Verbal Learning and Verbal Behavior, $1968,7,201-206$.

Kintsch, W. Models for free recall and recognition. In D. A. Norman (Ed.), Models of memory. New York: Academic Press, 1970.

Kruegen, L. E. The effect of acoustic confusability on visual search. American Journal of Psychology, 1970, 83, 389-400.

LEVY, B. A. Reading: Speech and meaning processes. Journal of Verbal Learning and Verbal Behavior, 1977, 16, 623-638.

Mayzer, M. S., Tresselt, M. E., \& Helbock, H. An exploratory study of mediational responses in anagram solving. Journal of Psychology, 1964, 57, 263-274.

Meyer, D. E., Schvaneveldt, R. W., \& Ruddy, M. G. Functions of graphemic and phonemic codes in visual wordrecognition. Memory \& Cognition, 1974, 2, 309-321.

Olson, R., \& Schwartz, R. Single and multiple solution five letter words. Psychonomic Monograph Supplements, 1967, 2, 105-152.

Rubenstein, H., \& Lewis, S. S., \& Rubenstein, M. A. Evidence for phonemic recording in visual word recognition. Journal of Verbal Learning and Verbal Behavior, 1971, 10, 645-657.

SCHWARTz, R. Anagram solving: A function of the frequency of vowel-consonant pattern. Psychonomic Science, 1968, 13, 229-230.

Solso, R. L. Cognitive psychology. New York: Harcourt, Brace, Jovanovich, 1979.

Solso, R. L., Topper, G. E., \& MaceY, W. H. Anagram solution as a function of bigram versatility. Journal of Experimental Psychology, 1973, 100, 259-263.

ThoRndike, E. L., \& Longe, I. The teacher's word book of 30,000 words. New York: Bureau of Publications, Teacher's College, Columbia University, 1944.

Tresselt, M. E., \& Mayznen, M. S. Normative solution times for a sample of 134 solution words and 378 associated anagrams. Psychonomic Monograph Supplements, 1966, 1, 293-298.

UnDE Rwood, B. J. Attributes of memory. Psychological Review, $1969,76,559-573$.

\section{NOTE}

1. This viewpoint was suggested to us by an anonymous reviewer. 
Appendix A

Anagram Solution Times and Proportions of Problems Solved in Experiment 1

\begin{tabular}{|c|c|c|c|c|c|c|c|c|c|c|c|c|c|}
\hline \multirow{3}{*}{$\begin{array}{l}\text { Solution } \\
\text { Word }\end{array}$} & \multirow[b]{3}{*}{ Anagram } & \multicolumn{9}{|c|}{ Solution Time } & & & \\
\hline & & \multicolumn{3}{|c|}{ Mean } & \multicolumn{3}{|c|}{ SD } & \multicolumn{3}{|c|}{ Median } & \multicolumn{3}{|c|}{ Proportion Solved } \\
\hline & & $\mathrm{CP}$ & V & IP & $\mathrm{CP}$ & V & IP & $\mathrm{CP}$ & V & IP & $\mathrm{CP}$ & V & IP \\
\hline BASIC & IACSB & 2.86 & 4.05 & 3.55 & 1.71 & 4.02 & 2.43 & 2.5 & 2.5 & 2.5 & 1.00 & .95 & 1.00 \\
\hline CABIN & CIANB & 4.68 & 6.36 & 6.41 & 3.31 & 4.83 & 4.25 & 4.2 & 4.0 & 5.2 & 1.00 & .86 & .95 \\
\hline CABLE & LBACE & 6.77 & 5.64 & 5.55 & 5.79 & 3.18 & 3.73 & 3.8 & 5.8 & 4.3 & .91 & 1.00 & 1.00 \\
\hline FACET & FCATE & 9.41 & 11.91 & 10.73 & 6.82 & 3.67 & 6.14 & 6.5 & 11.5 & 9.5 & .73 & .68 & .64 \\
\hline FOCUS & SUCOF & 3.23 & 3.36 & 4.59 & 3.65 & 3.31 & 4.06 & 2.2 & 3.2 & 3.8 & .95 & 1.00 & .95 \\
\hline GIANT & TNGAI & 4.45 & 7.18 & 8.18 & 4.91 & 5.80 & 6.00 & 2.4 & 4.5 & 6.5 & .91 & .82 & .77 \\
\hline HABIT & TBAHI & 2.09 & 2.41 & 2.36 & 1.20 & 1.07 & .22 & 1.9 & 2.2 & 2.1 & 1.00 & 1.00 & 1.00 \\
\hline HUMAN & AMNUH & 2.27 & 3.45 & 3.95 & 1.44 & 2.66 & 3.82 & 1.8 & 3.0 & 2.8 & 1.00 & 1.00 & .95 \\
\hline HUSKY & SHYKU & 8.14 & 9.86 & 13.41 & 6.63 & 5.30 & 5.88 & 4.5 & 7.8 & 17.6 & .73 & .64 & .45 \\
\hline LABOR & ROALB & 6.77 & 5.73 & 5.73 & 5.99 & 4.23 & 3.83 & 5.5 & 3.5 & 4.8 & .82 & .95 & .95 \\
\hline LIVER & VLEIR & 5.14 & 6.50 & 5.82 & 4.73 & 4.75 & 1.43 & 3.3 & 4.5 & 4.6 & .91 & .95 & .95 \\
\hline LOGIC & LCOIG & 2.64 & 3.45 & 3.36 & 2.22 & 3.75 & 5.32 & 1.8 & 2.5 & 2.9 & 1.00 & 1.00 & 1.00 \\
\hline MAGIC & MGCAI & 3.82 & 4.68 & 4.55 & 4.34 & 4.31 & 4.24 & 2.1 & 2.2 & 2.3 & 1.00 & .95 & .95 \\
\hline MAJOR & OJARM & 3.23 & 4.41 & 3.77 & 3.58 & 4.82 & 3.85 & 2.1 & 2.9 & 2.5 & .95 & .91 & .95 \\
\hline MINOR & NRIOM & 10.41 & 8.00 & 11.45 & 6.30 & 2.39 & 5.20 & 7.2 & 7.5 & 9.5 & .73 & .95 & .64 \\
\hline MODEL & DLOME & 5.32 & 7.77 & 7.73 & 5.61 & 4.96 & 5.65 & 3.0 & 6.8 & 8.0 & .91 & .86 & .86 \\
\hline MOVIE & IMEVO & 4.59 & 5.73 & 5.00 & 4.90 & 4.68 & 3.09 & 2.3 & 4.0 & 4.2 & .91 & .91 & 1.00 \\
\hline MUSIC & SCIUM & 1.91 & 1.86 & 2.32 & 1.62 & 1.01 & 1.46 & 1.3 & 1.5 & 2.0 & 1.00 & 1.00 & 1.00 \\
\hline NOBLE & NELBO & 3.73 & 4.14 & 5.14 & 4.09 & 3.14 & 4.06 & 2.5 & 3.0 & 3.7 & .95 & 1.00 & 1.00 \\
\hline NOVEL & LNEVO & 2.64 & 3.64 & 4.23 & 1.72 & 3.96 & 3.96 & 2.2 & 2.4 & 3.1 & 1.00 & .95 & .95 \\
\hline PATIO & POTAI & 10.64 & 13.23 & 11.64 & 6.57 & 5.94 & 5.68 & 11.2 & 17.5 & 10.5 & .73 & .50 & .59 \\
\hline PILOT & TLIOP & 5.64 & 5.32 & 4.27 & 5.75 & 4.95 & 4.83 & 3.0 & 2.2 & 2.7 & .86 & .91 & .91 \\
\hline RADIO & AIROD & 8.55 & 6.36 & 7.82 & 5.68 & 5.14 & 4.91 & 6.5 & 4.5 & 5.8 & .82 & .91 & .82 \\
\hline RAPID & IPRDA & 3.82 & 5.86 & 4.00 & 4.12 & 4.26 & 1.52 & 2.4 & 3.4 & 3.2 & 1.00 & .91 & 1.00 \\
\hline ROBIN & BRNOI & 7.14 & 7.59 & 6.14 & 5.49 & 5.56 & 6.48 & 3.5 & 5.0 & 4.5 & .82 & .86 & .82 \\
\hline TABLE & AELBT & 4.00 & 2.95 & 3.82 & 4.20 & 3.36 & 5.69 & 2.0 & 2.1 & 2.5 & 1.00 & .95 & .91 \\
\hline TOKEN & OTEKN & 2.05 & 2.77 & 2.82 & .88 & 2.41 & 1.11 & 2.0 & 2.4 & 2.8 & 1.00 & 1.00 & 1.00 \\
\hline TONIC & OTCIN & 8.14 & 9.00 & 8.32 & 5.12 & 4.52 & 5.99 & 6.5 & 6.5 & 6.0 & .86 & .82 & .86 \\
\hline VAPOR & AOVPR & 2.50 & 3.00 & 2.59 & 1.23 & 2.32 & 1.15 & 2.3 & 2.3 & 2.5 & 1.00 & 1.00 & 1.00 \\
\hline WAGON & ANOWG & 6.73 & 5.86 & 6.73 & 5.23 & 3.67 & 5.36 & 3.4 & 5.0 & 4.5 & .82 & .95 & .86 \\
\hline
\end{tabular}

Note-Results are presented for each anagram in the correct phonemic (CP), visual (V), and incorrect phonemic (IP) groups.

Appendix B

Anagram Solution Times and Proportions of Problems Solved for Each Anagram in Experiment 2

\begin{tabular}{|c|c|c|c|c|c|c|c|c|c|}
\hline \multirow{3}{*}{$\begin{array}{c}\text { Solution } \\
\text { Word }\end{array}$} & \multirow[b]{3}{*}{ Anagram } & \multicolumn{6}{|c|}{ Solution Time } & & \\
\hline & & \multicolumn{2}{|c|}{ Mean } & \multicolumn{2}{|c|}{ SD } & \multicolumn{2}{|c|}{ Median } & \multicolumn{2}{|c|}{ Proportion Solved } \\
\hline & & $\mathrm{CP}$ & IP & $\mathrm{CP}$ & IP & $\mathrm{CP}$ & IP & $\mathrm{CP}$ & IP \\
\hline CABIN & CANIB & 20.39 & 19.74 & 7.37 & 8.73 & 25.00 & 25.00 & .38 & .27 \\
\hline CABLE & CALEB & 19.79 & 20.69 & 5.38 & 7.02 & 25.00 & 25.00 & .35 & .35 \\
\hline CHIME & MECHI & 8.82 & 13.93 & 8.54 & 7.19 & 5.80 & 14.58 & .77 & .69 \\
\hline CLOSE & SECLO & 8.38 & 9.27 & 9.81 & 8.80 & 3.48 & 4.12 & .77 & .85 \\
\hline DECAY & AYDEC & 15.82 & 16.94 & 9.43 & 9.39 & 17.90 & 25.00 & .62 & .46 \\
\hline GIANT & NAGIT & 23.41 & 23.10 & 4.25 & 5.51 & 25.00 & 25.00 & .15 & .12 \\
\hline HOUSE & ESHOU & 6.32 & 7.61 & 7.97 & 7.44 & 1.76 & 5.36 & .92 & .92 \\
\hline HUMAN & ANHUM & 4.05 & 5.88 & 5.09 & 6.52 & 2.01 & 2.56 & .96 & .96 \\
\hline HUSKY & HUKYS & 17.86 & 18.33 & 8.87 & 9.08 & 25.00 & 25.00 & .46 & .38 \\
\hline JOKER & JOREK & 19.67 & 21.50 & 8.24 & 7.32 & 25.00 & 25.00 & .46 & .23 \\
\hline LOGIC & GLOCI & 14.52 & 14.28 & 9.44 & 9.72 & 12.44 & 15.86 & .62 & .62 \\
\hline LUCID & LUDIC & 18.31 & 17.75 & 8.52 & 10.08 & 25.00 & 25.00 & .46 & .35 \\
\hline MAGIC & ICMAG & 3.59 & 8.21 & 5.49 & 9.27 & 1.76 & 3.10 & .96 & .85 \\
\hline MAJOR & MAROJ & 15.81 & 16.11 & 10.06 & 10.61 & 22.01 & 25.00 & .50 & .46 \\
\hline RADIO & DOIRA & 18.37 & 17.21 & 8.44 & 8.94 & 25.00 & 24.33 & .50 & .50 \\
\hline VITAL & LATVI & 19.14 & 17.06 & 7.70 & 8.94 & 25.00 & 24.18 & .42 & .54 \\
\hline WAGON & WANOG & 12.77 & 16.36 & 9.83 & 10.42 & 10.26 & 25.00 & .65 & .42 \\
\hline YOUTH & THYOU & 7.50 & 7.36 & 7.58 & 7.41 & 4.05 & 3.96 & .88 & .88 \\
\hline
\end{tabular}

Note $-C P=$ correct phonemic $; I P=$ incorrect phonemic. 